http://dergipark.gov.tr/ataunizfd

\title{
Mekansal Termal Konfor Açısından Atatürk Üniversitesi Yerleşkesi Termal Kamera Görüntülerinin Analizi
}

\author{
Murat ZENGIN1 ${ }^{1}$ Sevgi YILMAZ ${ }^{*}$ iD Başak ERTEM MUTLU ${ }^{2}$ \\ ${ }^{1}$ Pamukkale Üniversitesi, Mimarlık ve Tasarım Fakültesi, Peyzaj Mimarlığı Bölümü, Denizli, Türkiye \\ ${ }^{2}$ Atatürk Üniversitesi, Mimarlık ve Tasarım Fakültesi, Peyzaj Mimarlığı Bölümü, Erzurum,Türkiye \\ (*Sorumlu yazar e-mail: syilmaz_68@hotmail.com) \\ DOI: 10.17097/ataunizfd.535209 \\ Geliş Tarihi (Received Date): 04.03.2019 \\ Kabul Tarihi (Accepted Date): 12.06.2019

\begin{abstract}
ÖZ: Kentsel nüfusun hızla arttığı yaşam alanlarında, konut ihtiyacını karşılamak için yapılan çalışmalar sonucunda başta açık-yeşil alanların azalması olmak nedeniyle, hava kirliliği, çarpık kentleşme gibi çeşitli çevre sorunları ortaya çıkmakta ve bu durum kentlerin termal konforunu olumsuz yönde etkilemektedir. Atatürk Üniversitesi Yerleşkesi içinde yer alan farklı niteliklere sahip mekanlar ile çeşitli renklerdeki doğal otsu bitki örtüsü ve mevsimlik bitkilerin yüzey sıcaklıkları termal kamera ile kaydedilmiştir. 2018 yılı Temmuz ayında havanın açık olduğu zamanda, bakı, rakım ve mevki olarak birbirine yakın mekanlarda bulunan ortamlardan alınan kayıtlardan, 6 tanesi seçilerek, bu alanlardaki 12 farklı niteliğe sahip mekan saat 15:00' e göre analiz edilmiştir. Alınan ölçümler ve yapılan değerlendirmeler sonucunda; doğal otsu bitkilerin ortamın mevcut sıcaklık değerine göre daha serin bir ortam oluşturduğu, yapısal alanların ise en yüksek sıcaklık değerine sahip olduğu tespit edilmiştir. Benzer biçimde, çim derzli kaldırımın, andezit taş kaldırımdan ortalama olarak $12.0^{\circ} \mathrm{C}$ daha serin çıktığı belirlenmiştir. Yapılan analiz ve değerlendirmeler neticesinde, kentsel alan planlamalarında termal konforun sağlanması açısından doğal otsu bitkilerin kullanımının önemli olduğu, planlama açısından iklim faktörünün kullanımının gerekliliği vurgulanarak önerilerde bulunulmuştur.
\end{abstract}

Anahtar Kelimeler: Termal kamera, Doğal otsu bitki, Mevsimlik bitkiler, Termal konfor

Atatürk University Campus in terms of Spatial Thermal Comfort Analysis of Thermal Camera Images

\begin{abstract}
Various environmental problems such as decreased outdoors/green spaces, air pollution, distorted urbanization emerge and cause lower thermal comfort in the cities as a result of the activities carried out to meet the need for housing in the residential areas where the urban population is rapidly increasing. Thermal cameras are used to record the surface temperature of spaces with different characteristics in Atatürk University Campus; the natural herbaceous plants in various colors and seasonal plants. 6 of records made in July 2018 in clear weather with similar characteristics in terms of their position to the sun, altitude, and location are selected and 12 locations with disparate characteristics in those records are analyzed according to 15:00 o'clock. As a result of the measurements and evaluations, it was noted that natural herbaceous plants form a cooler environment compared to the current temperature of the environment and asphalt has the highest temperature value in conditions. Also, it was determined that the grass joint pavement is on average $12.0{ }^{\circ} \mathrm{C}$ cooler than the stone pavement with andesite material. As a result of the analyses and evaluations, some suggestions were developed by emphasizing the importance of natural herbaceous plants in the provision of thermal comfort in urban area planning and the necessity of the use of climate factor in terms of planning.
\end{abstract}

Keywords: Thermal camera, Native herbaceous plants, Seasonal plants, Thermal comfort

\section{GÍRİş}

Son yillarda Birleşmiş Milletler Dünya Şehirleşme Raporlarına göre kentlerde nüfus yoğunluğu belirgin bir artış göstermektedir (United Nations, 2018). Buna bağlı olarak kentler her geçen gün biraz daha büyümekte ve birim alandaki nüfus yoğunluğu artmaktadır. Planlı olmayan bu kentsel gelişim, yaşam alanlarının kalite standartlarını olumsuz etkilemekte, hava kirliliğinden, enerji tüketiminin artmasına ve termal açıdan konforsuz mekanlara kadar birçok çevre sorununu beraberinde getirmektedir. Aynı zamanda, artan kent nüfusunun ihtiyaçlarını karşılamak için ihtiyaç duyulan konut alanları açık yeşil alanların azalmasına yol açmaktadır. Açık-yeşil alanlar bilinen birçok fiziksel özelliklerinin yansıra (Payton et al., 2008; Nordh et al., 2011), psikolojik açıdan da önemli katkılar sunarlar (Parsons and Daniel, 2002; Carlson 2010; Nordh et al., 2011). Kentlerde, farklı niteliklere sahip yerleşim alanlarında termal konfor değerlerini belirlemek amacını taşıyan çok sayıda çalışma bulunmaktadır (Unger, 1999; Y1lmaz et al., 2007; Bulgan vd., 2014; Dikhan et al., 2018; Canan et al., 2019).

Termal konforun belirlenmesinde basit ve karmaşık olarak isimlendirilen birçok iklim modeli kullanılmakta, zaman zaman geçmiş yıllara ait meteorolojik veriler ile geleceğe dönük senaryolarda üretilebilmektedir (De Ridder, 2015; Y1lmaz et al., 2018a; Y1lmaz et al., 2018b). Termal konforlu mekanları belirlemede kullanılan modellerin yanı sıra son yıllarda termal kamera kullanımı da bu alanda hız kazanmıştır. İnsansız hava aracı ile de kayıt alınabilen bu kameralar sayesinde yüzey sıcaklıklarının ölçümünü yapabilmektedir. İklim odaklı çalışmalarda, Termal Kameralar, kentsel yaşam alanlarının mevcut durumlarının tespiti ve tasarımlarda ileriye dönük iyileştirme senaryoları çalışmalarında kullanılmaktadır (Smigaj et al., 2015; Ginner et al., 2015; Aubrecht et al., 2016; Y1lmaz vd., 2016; Irmak et al., 2018; Mutlu et al., 2018). 
Erzurum kentinde, Y1lmaz vd. (2017)'de yaz ayında doğal ve egzotik mevsimliklerin termal kamera ile saat 13:00'e göre analizini yapmışlardır. Yapılan analiz sonucunda otsu bitkilerde yüzey sıcaklıklarının $3.2^{0} \mathrm{C}$ daha düşük olduğu belirlenmiştir. Egzotik veya yeşil çim alanların ise genellikle sulamadan kaynaklanan bir serinliğe sahip olduğu ifade edilmiştir.

Benzer biçimde Aguiar et al. (2014), kentsel alanlarda kullanılan doğal ve egzotik ağaç türlerinin gölgeleme etkilerini tespit etmek amacıyla termal kamera ile ölçümler gerçekleştirmişler ve kent genelinde tespiti yapılan benzer büyüklük ve konumda bulunan 3 doğal ağaç ile 3 egzotik ağaç altında düzenli değerlendirmeler gerçekleştirmişlerdir. Değerlendirme sonucunda doğal ağaçların altında bulundukları yüzeylerin ortalamada $2.0^{\circ} \mathrm{C}$ daha serin olduğu, bu nedenle doğal türlerin tercih edilmesi gerekliliği vurgulanmıştır.

Leuzinger and Körner (2007) tarafından yapılan çalışmada ise yüksek çözünürlüklü termal kamera ile 35 m yükseklikten ağaç yüzey sıcaklıkları ölçmüş ve hava sıcaklığı ile bitki yüzey sıcaklıklarının yakın değerlerde olduğunu tespit etmişlerdir. Yine aynı çalışmada ibreli bitki yüzeylerinin geniş yapraklı bitkilere göre daha düşük yüzey sıcaklığına sahip olduklarını belirlemiştir. Takebayashi and Moriyama (2009) ise, termal kamera ile yapmış oldukları çalışmada, otoparklardaki sert yüzeylerin kentsel 1sıyı artırdığını belirlemişlerdir.

Kentleşme hızına bağlı olarak azalan açık-yeşil alanlar, kentlerde nefes alacak ve insanlara huzur verecek mekanlarında kısıtlanmasına yol açmaktadır. $\mathrm{Bu}$ bağlamda, yerel yönetimlerin çevreyi yeşil alan bakımından zenginleştirme çabaları önemlidir. Yeşil alan oluştururken sıklıkla kullanılan mevsimlik bitkiler yerine, alternatif olarak doğal otsu bitkilerin kullanılmasının gerekliliği üzerinde durulması gereken bir konu olarak gündemde tutulmalıdır. Bunun nedeni bu tip bitkilerin bakım, yetiştirme, adaptasyon yanı sıra dikim maliyetlerinin de yüksek olmasıdır. Yerel yönetimler bu bitkileri genellikle bir veya iki yılda bir olmak üzere sürekli yenilemektedir. $\mathrm{Bu}$ tip bitkiler dikiminden sökümüne kadar bakım, sulama isteyen ve maliyet gerektiren bitkilerdir. Oysa doğal olarak yetişen otsu bitkilerin herhangi bir bakıma ihtiyacı bulunmamaktadır (Irmak ve Yılmaz, 2016). Aynı zamanda, diğer canlıların örneğin böcek ve kuşlarında barınmasına imkan veren mekanlar sağlamaktadırlar (Ikin et al., 2013). Erzurum ili, doğal otsu bitki örtüsü bakımından oldukça fazla tür çeşitliliğine sahiptir (Irmak ve Yılmaz, 2016).

$\mathrm{Bu}$ çalışmada, termal kamera görüntülerinden yararlanarak Erzurum kentsel mekanlarında yaz aylarında yaşanan sıcaklık stresininin azaltılmasına ve insanların termal konforlu mekanlardan daha fazla yararlanabilmesine yönelik olarak önerilerin geliştirilmesi amaçlanmıştır. Bu kapsamda, enerji odaklı, sürdürülebilir, termal konforlu kentleşme yaklaşımı vurgulanmış ve özellikle yeni yerleşim yerlerinde doğal bitkilerin kullanılmasının gerekliliğinin üzerinde durulmuştur. Elde edilen veriler 1şı̆̆ında benzer çalışmaların yerel yönetimlerce plan kararlarına aktarılmasının hususunda önerilerde bulunulmuştur. Çalışmanın özellikle kurak iklim etkisindeki yerleşimler başta olmak üzere Türkiye'nin diğer kentleri içinde yaygın etki oluşturabileceği düşünülmektedir.

\section{MATERYAL VE METOT}

Atatürk Üniversitesi yerleşkesinde yürütülen bu çalışmada Temmuz 2018'de 6 farklı nitelikteki istasyondan alınan termal kamera kayıtları incelenmiştir. Araştırma alanında havanın açık olduğu zamanda, aynı bakı ve rakıma sahip, mevki olarak birbirine yakın mekanlarda bulunan ortamlardan, saat 15:00'de yerden 1-1.5m yükseklikten alınan kayıtların 6'sı seçilerek analizleri yapılmıştır. Araştırma süresince 2018 Temmuz ayı içerisinde alınan 20 termal kamera kaydından 6 tanesi kullanılmıştır. Buna göre, istasyon 1 Rektörlük Kavşağı, istasyon 2 Kredi Yurtlar Kurumu Kavşağı, istasyon 3 Eczacılık Fakültesi yakını, istasyon 4 ve 5 Mimarlık ve Tasarım Fakültesi yakını, istasyon 6 ise Atatürk Üniversitesi çiftlik binası girişinden oluşmaktadır (Şekil 1). Bu amaçla; Optris ${ }^{\circledR}$ PI-450 (Optris, Berlin, Germany), 7.5-13 $\mu \mathrm{m}$. çözünürlük aralığında, 382 x 288 piksel, $\pm 2{ }^{\circ} \mathrm{C}$ doğruluk ayarına sahip ve $0.1{ }^{\circ} \mathrm{C}$ hassasiyetli termal kamera kullanılmıştır. Ayrıca hava sıcaklığının yüzey sıcaklıkları ile karşılaştırmak için WS300 hassas sıcaklık ölçer ile ortamın sicaklık verileri ölçülmüştür. Termal kamera ile ölçüm yapılan alanlardan sıcaklık ve rüzgar değerleri de saatlik ölçümler olarak kullanılmıştır. Elde edilen görüntüler üzerinden analizler yapılırken, görüntü üzerine ızgara formunda kareler atılarak her bir birim kareden yüzey sıcaklıkları elde edilmiştir. Termal kamera görüntüsü alınan istasyonların konum haritası Şekil 2'de verilmiştir. Çalışma kapsamında analiz edilen 6 istasyonun termal kamera görüntüsü içinde yer alan 12 adet farklı nitelikteki birim incelenmiştir. Analizi yapılan 12 birim alanı; Çim derzli kaldırım (1), Andezit Taş Kaldırım (2), Doğal sarı çiçekli otsu bitki (3), Doğal kırmızı çiçekli otsu bitki (4), Doğal beyaz çiçekli otsu bitki (5), Karışık çiçeksiz doğal otsu bitki (6), Toprak alan (7), Mevsimlik yeşil renkli bitki (8), Mevsimlik beyaz çiçekli bitki (9), Mevsimlik pembe çiçekli bitki (10), Asfalt yol (11), yağmur suyu birikintisi (12) içermektedir. Ancak 6 istasyona ait her bir görüntüde bu 12 birim alanın hepsi bulunmamaktadır. Görüntülerin seçimi yapılırken mümkün olduğu ölçüde fazla sayıda birimi barındırmasına dikkat edilmiştir. 


\section{Rüzgar Yönü ve Esme Sayıları Oranı}

Çalışma alanı içinde termal konforu etkileyen önemli faktörlerden biri rüzgar olarak belirlenmiştir (2150627 Nolu TÜBİTAK 1001 projesi; Li et al., 2019). Bu nedenle araştırma alanı için etkin olan rüzgar değerleri, Erzurum Meteoroloji 12. Bölge Müdürlüğ̈̈'nden temin edilmiştir. Uzun yıllar rüzgar yönü ve esme sayılarına bağlı olarak Erzurum kenti hakim rüzgar yönünün Kuzey Doğu yönlü olduğu görülmüştür. Mevsimsel olarak uzun yıllar rüzgar yönü ve esme sayıları oranına göre ilkbahar aylarında Güneybatı; Yaz aylarında Kuzeydoğu; Sonbahar aylarında Güneybatı, Batı ve Kuzeydoğu; Kış aylarında ise Batı ve Kuzeydoğu rüzgarlarının etkili olduğu tespit edilmiştir.

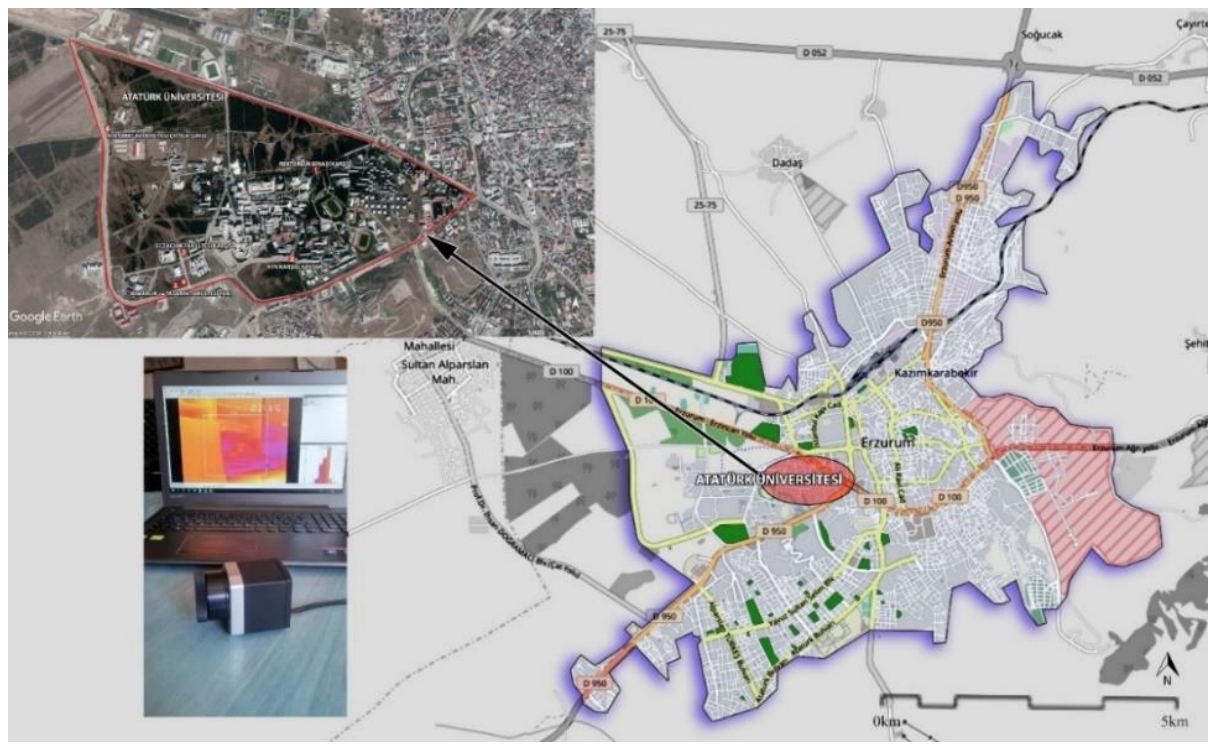

Şekil 1. Çalışma alanının konumu ve termal kamera kayıt işlemi görüntüsü (Google Earth)

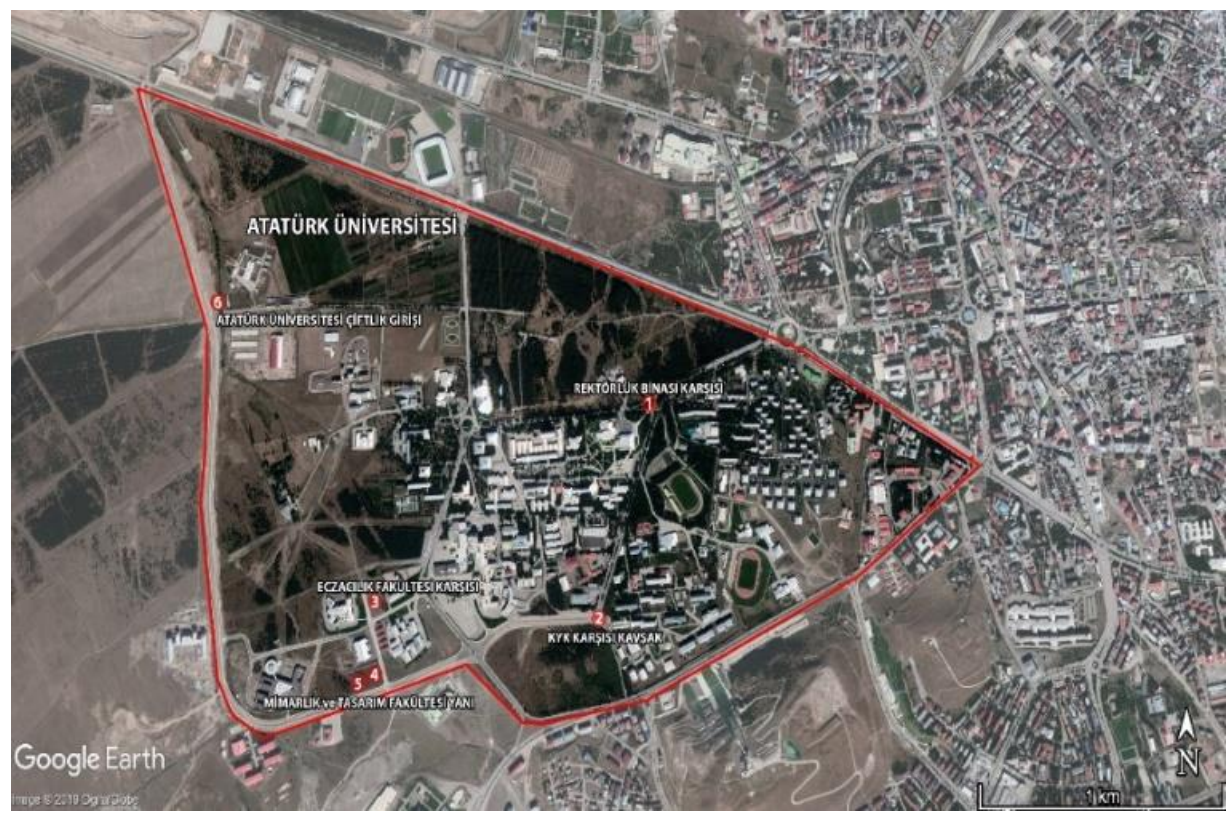

Şekil 2. İstasyon 1: Rektörlük kavşağı, İstasyon 2: Kredi Yurtlar Kurumu Kavşağı, İstasyon 3: Eczacılık Fakültesi yakını, İstasyon 4 ve 5: Mimarlık ve Tasarım Fakültesi yakını, İstasyon 6: Atatürk Üniversitesi çiftlik binası girişi 


\section{BULGULAR VE TARTIȘMA}

Analiz edilen 6 adet görüntü içinde yer alan 12 farklı birim için ayrı ayrı yüzey sıcaklık incelemeleri gerçekleştirilmiştir.

İstasyon 1: Yerleşke girişinde yer alan rektörlük kavşağ1 ve çevresine ait olan bu termal kamera görüntüsünde çim derzli kaldırım, asfalt ve mevsimlik bitkiler ağırlıklı olarak bulunmaktadır.

Yerleşke içinde çim derzli kaldırım ve yakın çevresindeki mevsimlik bitkilerin yüzey sıcaklıkları Şekil 3'de verilmiştir. Farklı renklere sahip olan mevsimlik bitkilerin renklerine göre yüzey sıcaklıkları değişiklik göstermektedir. İstasyon 2: Kredi Yurtlar Kurumu önünde, etrafı asfalt yolla çevrili ve içinde mevsimlik bitkiler bulunan bir kavşaktır. Yerleşke içindeki bu kavşağın görüntüleri analiz edilmiş ve Şekil 4'de verilmiştir. Etrafı tamamen açık ve güneş ışığına maruz kalan asfalt kaplamının, mevsimlik bitki bulunan alana göre sicaklıklarda faklılıklar tespit medilmiştir. İstasyon 3: Batı yerleşkesi içinde Eczacılık fakültesi yakınında yer alan istasyonda, ağırlıklı olarak andezit taş kaplı kaldırım ve etrafındaki doğal bitkiler yer almaktadır. Termal kamera görüntüsüne ait analiz ve yüzey sıcaklık değerleri Şekil 5'de verilmiştir. İstasyon 4: Mimarlık ve Tasarım Fakültesi yakınında bulunan istasyonda kaldırım ve çevresine ait görüntü ele alınmıştır. Şekil 6 'da verilen kaldırımın otsu bitkilerin daha uzun boylu olan kısmında ve kaldırıma gölge oluşturan kısımdaki yüzey sıcaklık analizleri verilmiştir. İstasyon 5: $\mathrm{Bu}$ istasyon, 4. İstasyonun yakınında bulunmakta ve tamamen doğal otsu bitkilerden oluşmaktadır. Mekanın yüzey sicaklık analizi ise Şekil 7'de verilmiştir. Analizde otsu bitkilerin olduğu mekanda çiçek renklerinin farklı yüzey sıcaklığına sahip olduğu belirlenmiştir. İstasyon 6: Atatürk Üniversitesi çiftlik binası girişi yakınlarında yer alan ve içinde yağmur suyu birikintisi bulunan mekanın yüzey sıcaklıkığı analiz edilmiştir. Analiz sonuçları Şekil 8'de verilmiştir. Etrafinda ağaç bulunmayan ve güneş 1şı̆̆ına maruz kalan kaldırım ve otsu bitkilerin sıcaklık değerleri arasındaki farklılıkları belirlenmiştir.

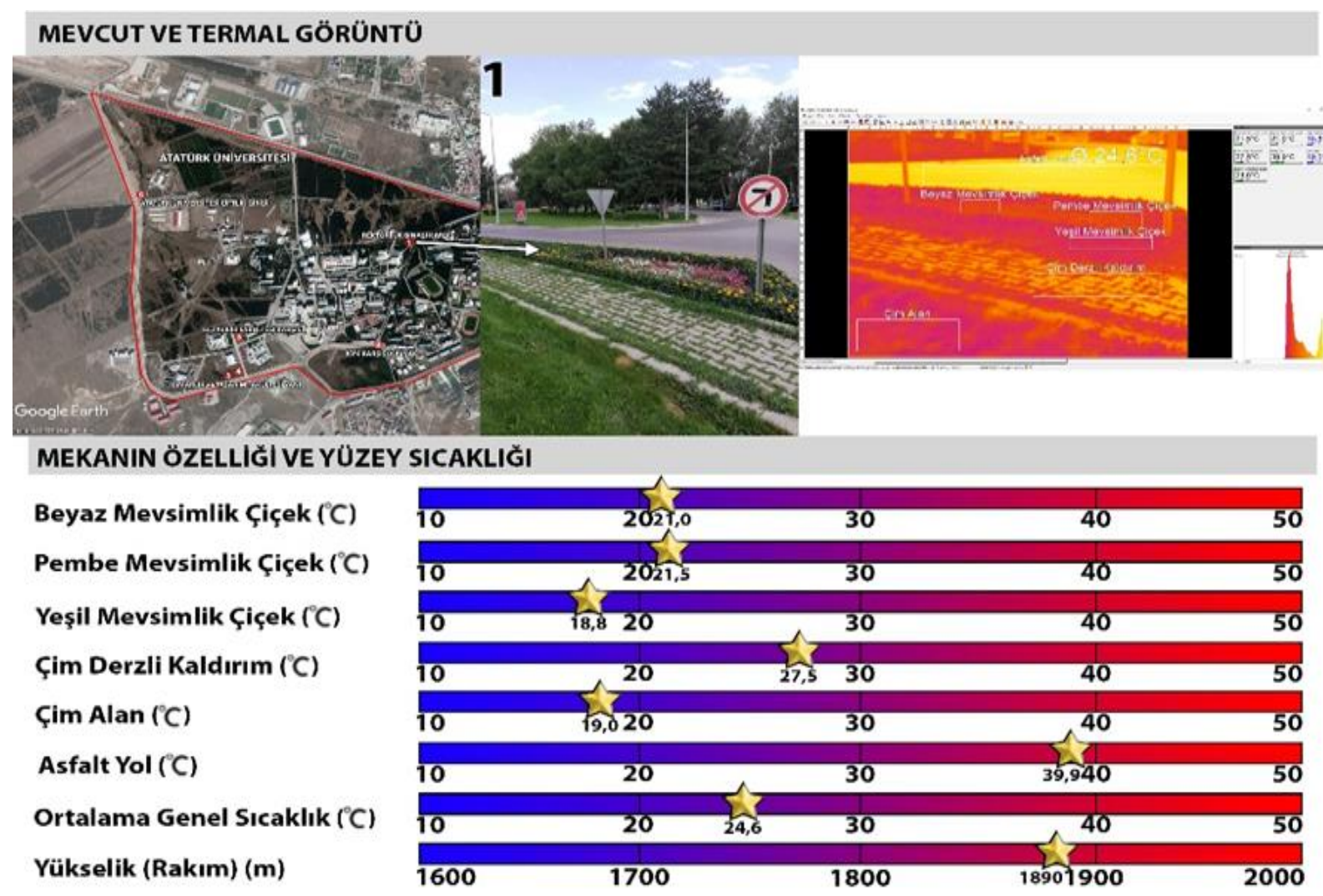

Şekil 3. İstasyon 1'de yer alan bitkisel ve yapısal yüzey sıcaklıkları 


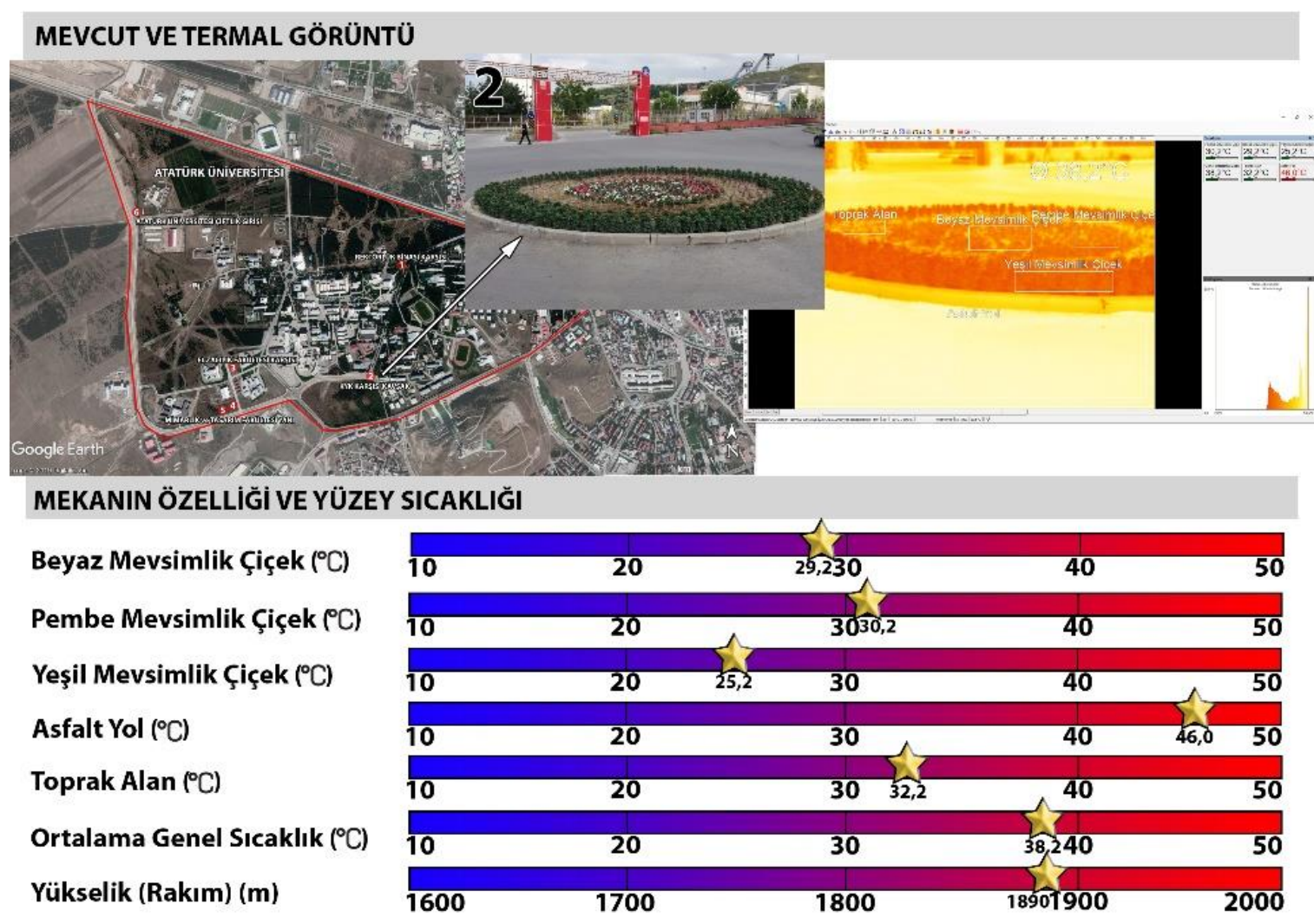

Şekil 4. İstasyon 2'de yer alan mevsimlik bitki ve asfalt sıcaklıkları arasındaki faklılıklar

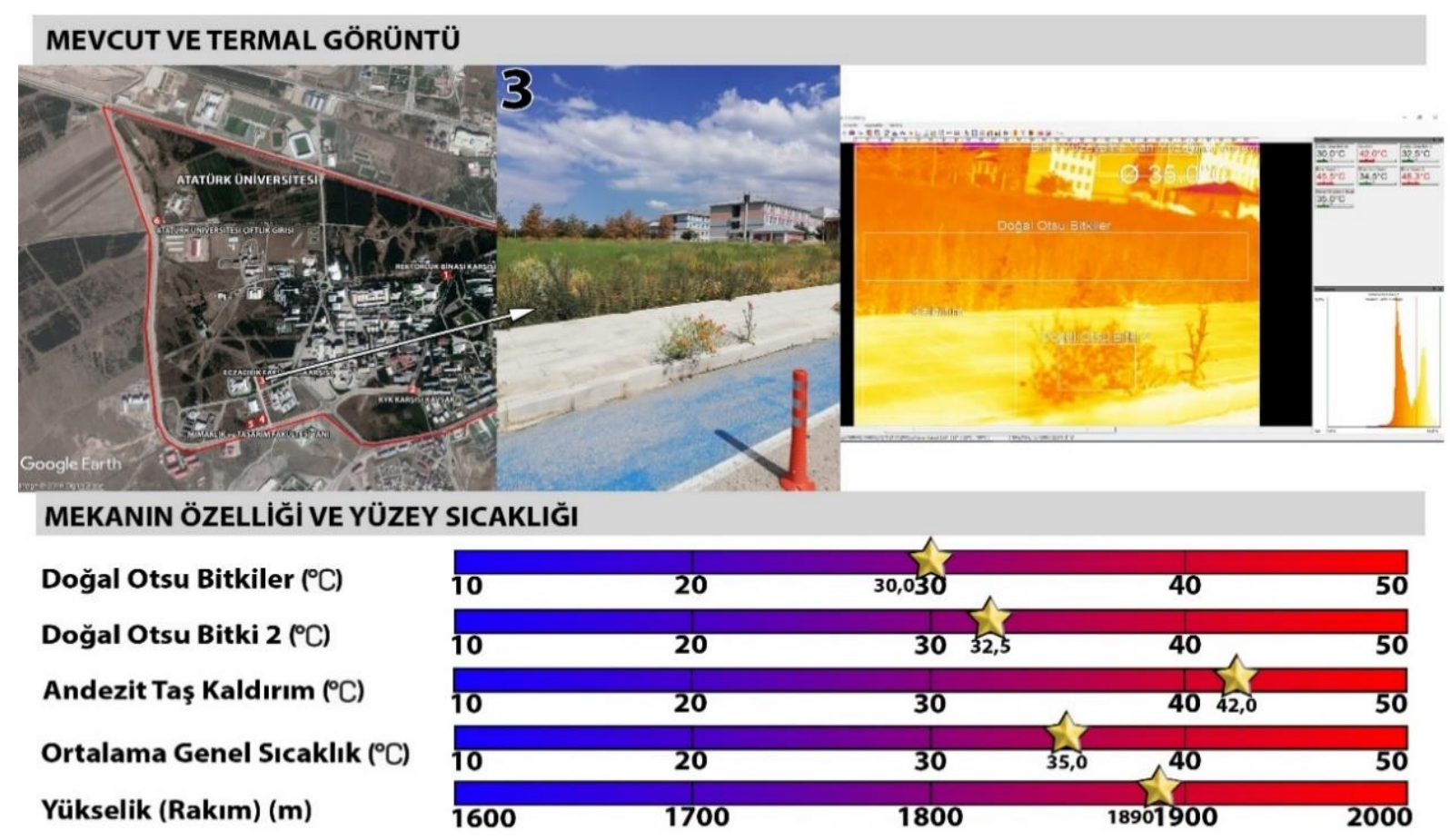

Şekil 5. İstasyon 3'de yer alan andezit taş kaldırım ve otsu bitkilerin yüzey sıcaklık değerleri 


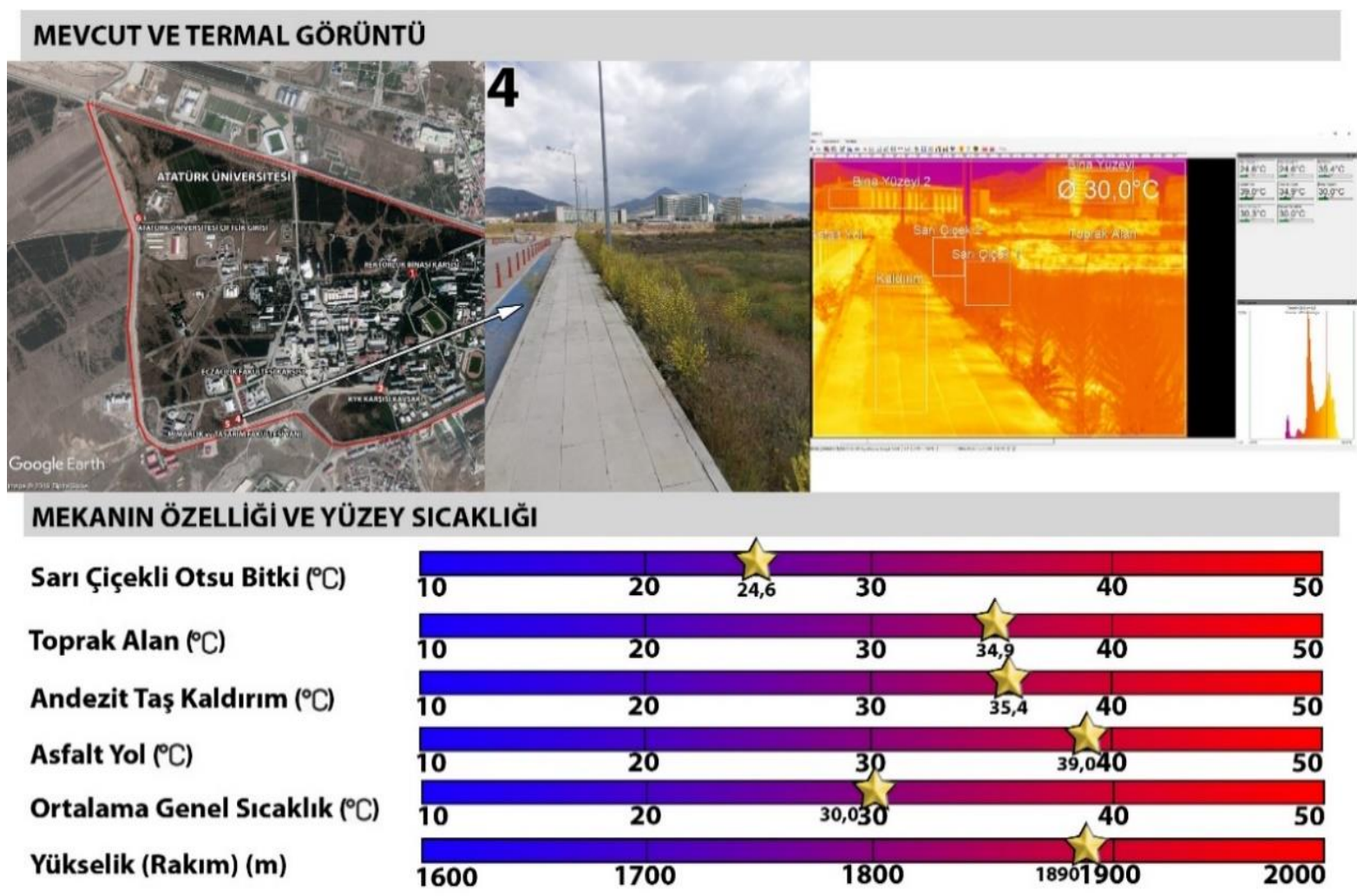

Şekil 6. İstasyon 4'de yer alan beton kaplama kaldırım, asfalt yol ve otsu bitkilerin yüzey sıcaklık analizi

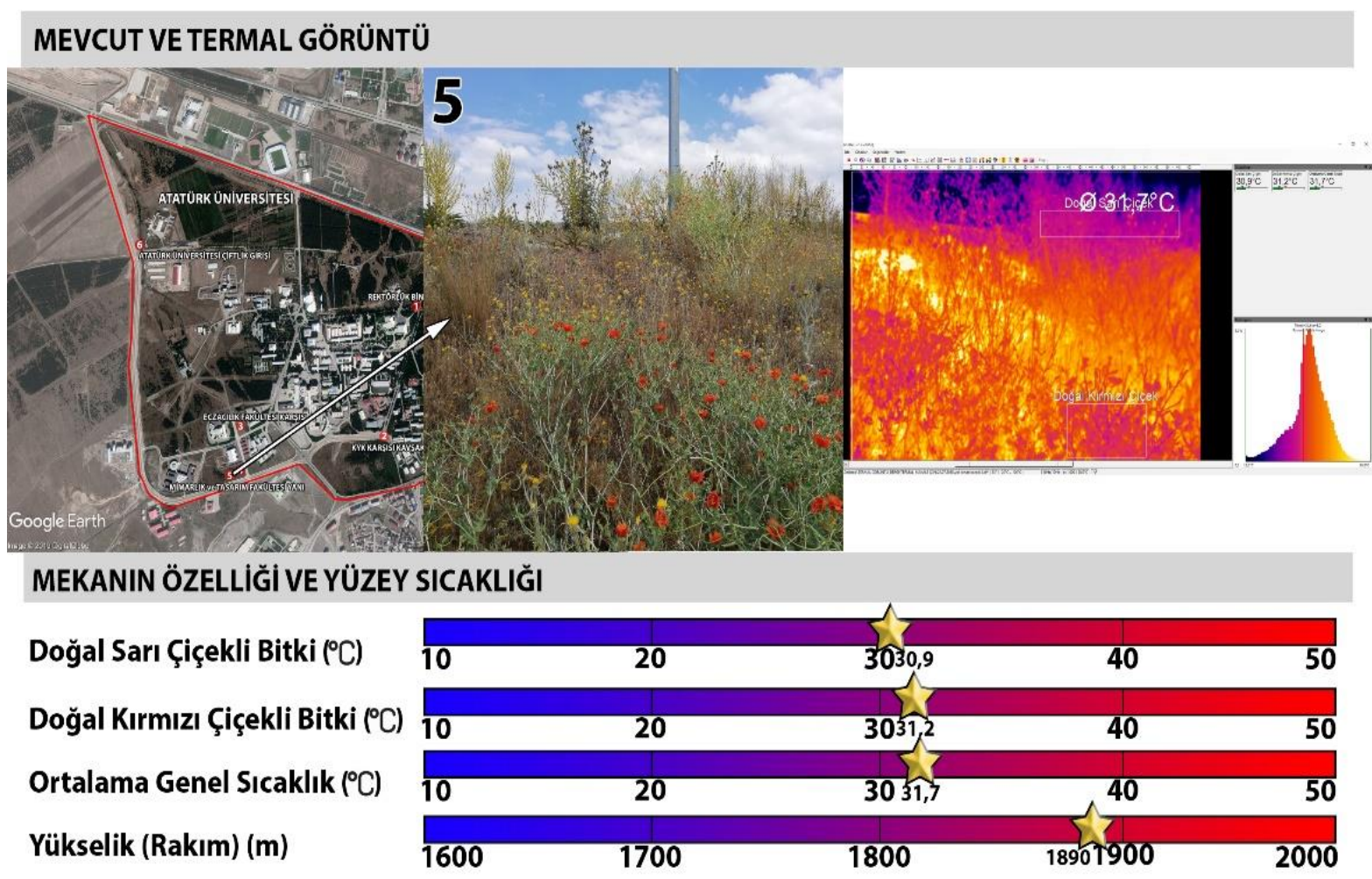

Şekil 7. İstasyon 5'de yer alan tamamen doğal otsu bitkilerin olduğu mekanın yüzey sıcaklık analizleri 
Atatürk Üniversitesi yerleşkesi genelinde 12 farklı birim alandan elde edilen yüzey sicaklık ölçümlerine ait ölçüm değerleri Çizelge 1'de verilmiştir.

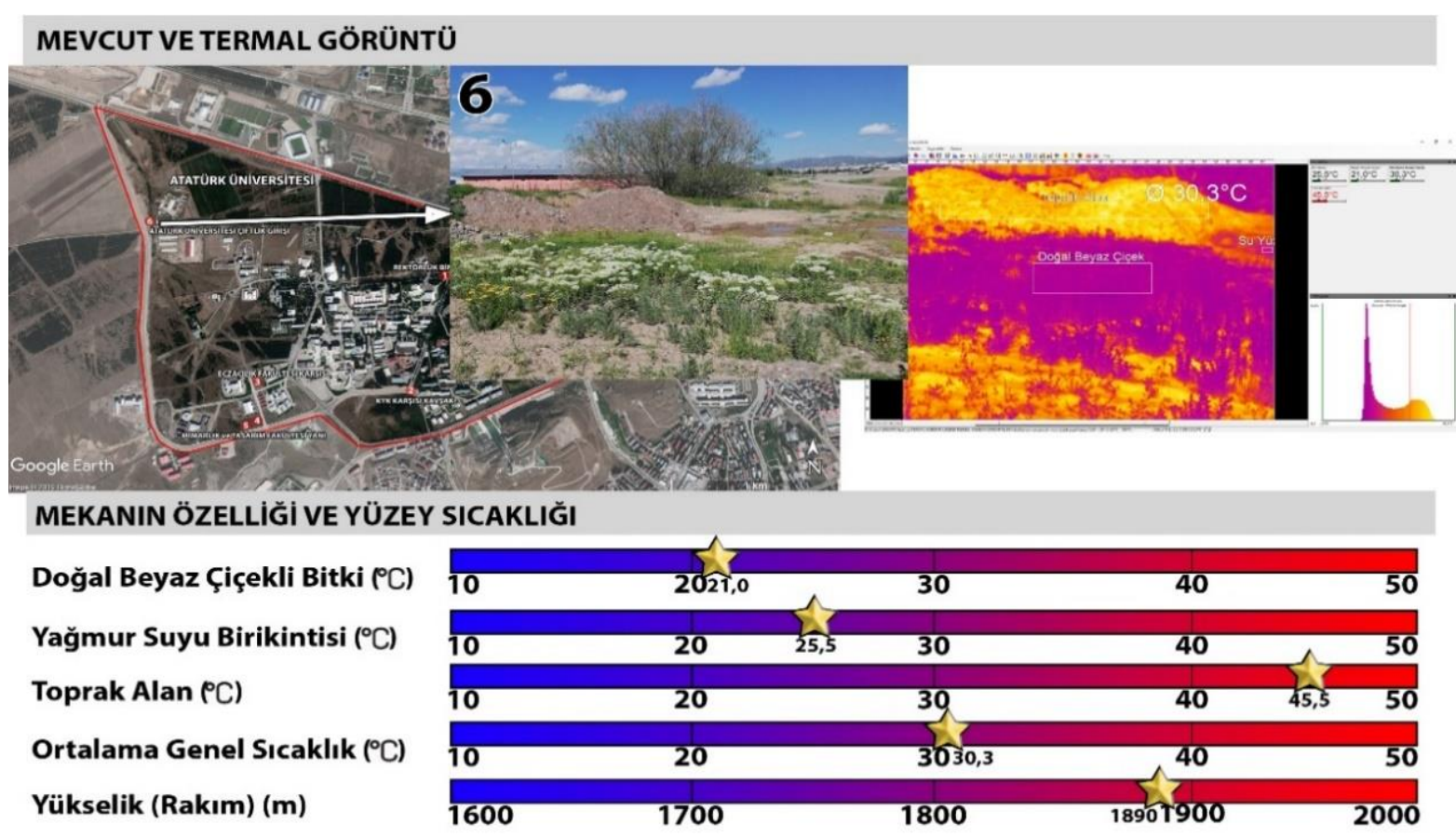

Şekil 8. İstasyon 6'da yer alan yağmur suyu birikintisinin yüzey sıcaklık analizi

Çizelge 1. Atatürk Üniversitesi Yerleşkesinde Temmuz 2018 ‘de termal kamera ile yapılan yüzey sıcaklık ölçüm değerleri

\begin{tabular}{|c|c|c|c|c|}
\hline $\begin{array}{c}\text { Yapısal ve Bitkisel Yüzey } \\
\text { Sıcaklık Ölçümleri }\end{array}$ & $n$ & $\begin{array}{c}\text { En Düşük } \\
\text { Yüzey Sicaklık ( } \\
\left.{ }^{0} C\right)\end{array}$ & $\begin{array}{c}\text { En Yüksek } \\
\text { Yüzey Sicaklığı } \\
\left({ }^{0} \mathrm{C}\right)\end{array}$ & $\begin{array}{c}\text { Ortalama } \\
\text { Yüzey Sicaklı̆̆ı } \\
\left({ }^{\circ} \mathrm{C}\right)\end{array}$ \\
\hline Çim derzli kaldırım $(1)$ & 30 & 18.8 & 34.1 & 26.5 \\
\hline Andezit taş kaldırım $_{(2)}$ & 30 & 32.3 & 42.8 & 38.7 \\
\hline Doğal sart çiçekli otsu bitki (3) & 30 & 24.4 & 38.6 & 32.0 \\
\hline Doğal kırmızı çiçekli otsu bitki (4) & 30 & 29.4 & 34.5 & 30.9 \\
\hline Doğal beyaz çiçekli otsu bitki ${ }_{(5)}$ & 30 & 19.9 & 24.6 & 21.5 \\
\hline Karlşık çiçeksiz doğal otsu bitki (6) & 30 & 22.6 & 34.7 & 28.2 \\
\hline 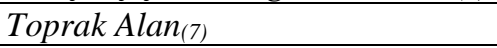 & 30 & 28.0 & 49.0 & 40.5 \\
\hline Mevsimlik yeşil renkli bitki $_{(8)}$ & 30 & 17.9 & 29.8 & 21.8 \\
\hline Mevsimlik beyaz çiçekli bitki ${ }_{(9)}$ & 30 & 20.0 & 31.7 & 24.7 \\
\hline Mevsimlik pembe çiçekli bitki $_{(10)}$ & 30 & 20.2 & 31.9 & 24.9 \\
\hline Asfalt Yol $(11)$ & 30 & 37.7 & 47.1 & 42.9 \\
\hline Yağmur suyu birikintisi $_{(12)}$ & 30 & 22.9 & 35.2 & 28.9 \\
\hline
\end{tabular}

Üniversite yerleşkesinde 6 farklı alanda yapılan termal kamera görüntü analizleri sonucunda elde edilen yüzey sıcaklık ortalama değerlerine göre çim derzli kaldırımlar $26.5^{\circ} \mathrm{C}$, andezit taş kaldırım 38.7 ${ }^{\circ} \mathrm{C}$, asfalt yol $42.9{ }^{\circ} \mathrm{C}$ çıkmıştır. Her koşulda asfalt yolun yüzey sicaklığı en yüksek değer olarak görülmektedir. Yağmur suyu birikintisinin olduğu alanın yüzey sıcaklık ortalaması $28.9^{\circ} \mathrm{C}$, mevsimlik bitkilerin (yeşil,beyaz, pembe) ortalama yüzey
Sıcaklığ $23.8^{\circ} \mathrm{C}$, doğal bitkilerin (Sarı, kırmızı, beyaz, karışık) ortalamsı ise $28.1^{\circ} \mathrm{C}$ çıkmıştır. Yapılan yüzey sicaklık analizlerine göre, 6 istasyonda da otsu bitki örüsü ve yağmur suyu birikintisinin olduğu tüm mekanlar, mevcut ortam sicaklığından daha serin olarak bulunmuştur. Buda kentsel mekanlarda özellikle yaz aylarında bitkisel alanlar, sulak alanlar ve su yüzeylerinin serinletici etkisini desteklemektedir (Depietri et al., 2012; Gou et al., 2014; Carol et al., 
2015). Termal kamera kaydı alınan mevsimlik bitkilerin ortam sıcaklığından daha düşük sıcaklığa sahip olmasının nedeni ise; bu bitkilerin sulanması nedeni ile ortamın serinlemesine katkı sağlamasından dolayı olduğu belirlenmiştir. Fotoğraftada görüldüğü gibi bitkiler yeni dikilmiş ve sulanmıştır. Çim derzli kaldırımın, andezit taş kaldırım ve asfalta göre daha serin çıktığı görülmektedir. Asfalt yolun yüzey sıcaklık ortalaması $42.9{ }^{\circ} \mathrm{C}$ ile en yüksek sıcaklık olarak ölçülmüştür. Nitekim kentsel mekanlarda asfalt ve beton yüzeyler gün boyu isınmakta ve bu 1sıy1 yansıtmaktadır. Buda ortamın sıcaklık artışını sağlayarak mikroklimayı olumsuz etkilemektedir. Bu nedenle kentsel mekanlarda kaldırımların kaplamasında kullanılan malzeme kentin termal konforu için önemlidir (Santamouris, 2013; Irmak et al., 2017).

Ortam sıcaklığ 1 ile otsu bitkilerin yüzey sıcaklığ1 karşılaştırıldığ 1 zaman ise daha serin çıktığ 1 saptanmıştır. Ölçüm alınan farklı bitki kompozisyonunda doğal bitkilerin mevcut ortam sicaklığına göre daha serin ortamlar oluşturduğu gözlemlenmiştir. Belirgin bir şekilde beyaz renkli otsu bitkilerde sıcaklık farkı olmasına karşın diğer renkli bitkilerde çok bariz bir sicaklı fark1 gözlemlenmemiştir.

\section{SONUÇ VE ÖNERILER}

Kentsel mekanlarda termal konfor canlıların kendini iyi hissetmesi için oldukça önemlidir. Termal konforlu mekanlar enerji tasarrufunun sağlanması açısındanda katkı sağlamaktadırlar. Kentsel mekanlarda ortamın soğutulması ve 1sitılmasında oldukça fazla enerjiye ihtiyaç duyulmaktadır. Bu bağlamda doğru planlama ve iklim odaklı çalışmalarla enerji tasarrufu yapılmasıda mümkün olmaktadır.

Kentlerin 1sınması ve kentsel isı adası oluşumu, soğutma için daha fazla enerji tüketimine yol açmaktadır. Bu amaçla yapılan çalışmada doğal otsu bitkilerin ortamı daha fazla serinletmesi bir avantaj olarak görülmelidir. Çünkü mevsimlik bitkiler işçilik, maliyet ve bakım giderleri anlamında oldukça masraflı ve her yıl yenileme ihtiyacı duyan bitkilerdir. Oysa doğal otsu bitkiler bakım istemeyen, her yıl yenilemeye ihtiyaç duymayan ekonomik açıdan avantajlı bitkilerdir. Günümüzde Avrupa peyzajı daha çok kurakçıl (kserofit) peyzaj düzenlemelerine ve kentsel mekanda doğal otsu bitkilerin kullanımına geçmiştir.

Elde edilen sonuçlara paralel olarak; Aguiar et al. (2014)'ın yaptığı çalışmaya göre de doğal ağaçlar egzotik ağaçlardan $2{ }^{\circ} \mathrm{C}$ daha serin mekanlar sağladığ 1 bulunmuştur. Yılmaz et al. (2017)'nin termal kamera ile otsu bitkiler üzerine yaptıkları çalışmada, doğal bitkileri ekzotik mevsimliklere göre $3.2^{\circ} \mathrm{C}$ daha serin olduğunu saptamışlardır. Günümüzde kentsel ısı adası problemi ile mücadele eden kentsel alanların doğal otsu bitkilerle bitkilendirilmesi önem arz etmektedir. Çalışmada elde edilen sonuçlara göre beyaz çiçek rengine sahip ya da açı renklerdeki otsu bitkiler daha serin bir ortam oluşturmaktadır. Ayrıca, kentsel mekanlarda kullanılması önerilen doğal otsu bitkiler, mekanda farklı canlılara da ev sahipliği yapacaktır. Örneğin böcekler, kuşlar bu mekanda yaşayarak ekolojik iyileşmeye katkı sağlayacaklardır. Bu aynı zamanda yerel yönetimler için ekonomik bir kazanç oluşturacaktır. $\mathrm{Bu}$ nedenle iyi bir termal konforlu kentleşme için yeni yerleşim alanlarında veya kentsel mekanda, doğal otsu bitkilere, peyzaj plantasyon projelerinde yer verilmelidir. Çiçekleri ile etkin peyzaj değerine sahip doğal otsu bitkilerin üretilmesi ve kentsel mekanlar da kullanılması, sürdürülebilir çevre içinde oldukça önemli bir katkı sağlayacaktır.

\section{BÍLGILENDÍRME}

Bu çalışmada yapılan ölçümler, TÜBİTAK'ın 2150627 numaralı projesinden alınan cihazlarla yapılmıştır.

\section{KAYNAKLAR}

Aguiar, A.C., French, K., Chisholm, L.A., 2014. A comparison of the ameliorating effects of native and exotic street trees on surface heat retention at dusk. Urb. Clim., 10: 56-62.

Aubrecht, D.M., Helliker, B.R., Goulden, M.L., Roberts, D.A., Still, C.J., Richardson, A.D., 2016. Continuous, long-term, high-frequency thermal imaging of vegetation: Uncertainties and recommended best practices. Agricultural and Forest Meteorology, 228: 315-326.

Bulgan, E., Yılmaz, S., Matzarakis, A., Irmak, M.A., 2014. Quantification of summer thermal bioclimate of different land uses in an urban city centre. IC2UHI3, October 13-15 2014, Venezia, Italy, pp: 523-534.

Canan, F., Golasi, I., Ciancio, V., Coppi, M., Salata, F., 2019. Outdoor thermal comfort conditions during summer in a cold semi-arid climate. A transversal field survey in Central Anatolia (Turkey), Building and Environment, 148 (1): 212-224.

Carlson, A., 2010, Contemporary Environmental Aesthetics and the Requirements of Environmentalism. Environmental Values, 19: 289-314.

Carol, E., Braga, F., Lio, C.D., Kruse, E., Tosi, L., 2015. Environmental isotopes applied to the evaluation and quantification of evaporation processes in wetlands: A case study in the Ajó Coastal Plain wetland, Argentina. Environ. Earth Sci. 74: 5839-5847.

Depietri, Y., Renaud, F.G., Kallis, G., 2012. Heat waves and floods in urban areas: a policyoriented review of ecosystem services. 
Integrated Research System for Sustainability Science, United Nations University, and Springer 2011, Sustain. Sci., 7: 95-107.

De Ridder, K., Lauwaet, D., Maiheu, B. 2015. "UrbClim - a fast urban boundary layerclimate model", Urban Climate, 12: 21-48.

Dikhan, M., Karsli F., Guneroglu, N., Guneroglu, A., 2018. Evaluation of urban heat island effect in Turkey, Arab.J.Geosci., (2018) 11:186, pp:1-20.

Ginner, S., Vogt, J., Tharang, A., Dettmann, S., Roloff, A., 2015. Role of street trees in mitigating effects of heat and drought at highly sealed urban sites. Landscape and Urban Planning, 143: 33-42.

Gou, Q.Q., Qu, J.J., Han, Z.W., 2014. Analysis of the microclimate and $\mathrm{CO}_{2}$ flux characteristics in arid desert wetland ecosystem in summer: A case study in Xihu desert wetland, Dunhuang, China. J. Earth Syst. Sci., 123: 1491-1499.

Ikin, K., Knight, E., Lindenmayer, D., Fischer, J., 2013. The influence of native versus exotic streetscape vegetation on the spatial distribution of birds in suburbs and reserves. Divers. Distrib., 19 (3): 294-306

Irmak, M.A., Y1lmaz, H., 2016. Efficiency of seasonal plants in cold climate zones.Biological Diversity and Conservation, 9(2): 157-168.

Irmak, M.A., Y1lmaz, S., Dursun, D., 2017. Effect of different pavements on human thermal comfort conditions. Atmósfera, 30 (4): 355-366.

Irmak, A., Yılmaz, S., Mutlu, E., Y1lmaz, H., 2018. Assessment of the effects of different tree species on urban microclimate. Environmental Science and Pollution Research, 25 (16): 1580215822.

Leuzinger, S., Korner, C., 2007. Tree species diversity affects canopy leaf temperatures in a mature temperate forest. Agricultural and Forest Meteorology, 146(1-2): 29-37.

Li, C., Wang, Z., Li, B., Peng, Z.-R., Fu, Q. 2019. Investigating the relationship between air pollution variation and urban form. Building and Environment, 147: 559-568.

Mutlu, B.E., Y1lmaz, S., Mutlu, E., 2018. Quantifying The Influence of Building Surface Materials on Thermal Comfort in Cold City. 6th annual international Conference on Architecture and Civil Engineering (ACE 2018), O.P, 4-15 May 2018, Singapore, pp: 524-527.

Nordh, H., Alalouch, C., Hartig, T., 2011. Assessing restorative components of small urban parks using conjoint methodology. Urban Forestry \& Urban Greening, 10: 95-103.

Payton, S., Lindsey, G., Wilson, J., 2008. Valuing the benefits of the urban forest: a spatial hedonic approach. J. Environ. Plan. Manage. (June 2012), pp: 37-41.
Parsons, R., Daniel, T.C., 2002. Good looking: in defense of scenic landscape aesthetics. Landscape and Urban Planning, 60(1): 43-56

Santamouris, M., 2013. Using cool pavements as a mitigation strategy to fight urban heat island-a review of the actual developments, Renew. Sustain. Energy Rev., 26: 224-240.

Smigaj, M., Gaulton, R., Barr, S.L., Suárez, J.C., 2015. Uav-Borne Thermal Imaging for Forest Health Monitoring: Detection of Diseaseinduced Canopy Temperature Increase. The International Archives of Photogrammetry, Remote Sensing and Spatial information Sciences, 40 (3): 349-354.

Takebayashi, H., Moriyama, M., 2009. Study on the urban heat island mitigation effect achieved by converting to grass-covered parking. Solar Energy, 83 (8): 1211-1223.

Unger, J, 1999. Comparisons of urban and rural bioclimatological conditions in the case of a Central-European city. International Journalof Biometeorology, 43 (3): 139-144.

United Nations, 2018. The world's cities in 2018: data booklet. Department of Economic and SocialAffairs,http://www.un.org/en/events/citie sday/assets/pdf/the_worlds_cities_in_2018_data _booklet.pdf. (Accessed date: February 6, 2019)

Y1lmaz, S., Toy, S., Y1lmaz, H., 2007. Human Thermal Comfort over Three Different Land Surfaces during summer in the City of Erzurum, Turkey, Atmosfera, 20 (3): 289-297.

Yılmaz, H., Yılmaz, S., Yavaş, M., Mutlu, E., Koç, A., 2016. Climate-sensitive Pavement Modelling for Pedestrian Ways. 4th international Conference on Countermeasures to Urban Heat island (UHI). Procedia Engineering, 169: 408-415

Y1lmaz, S., Mutlu, E., Y1lmaz, H., 2017. Effects of Plant Usage on Urban Thermal Comfort for Sustainable Cities. 8th Atmospheric Science Symposium, Oral presentation, ATMOS 2017, 1-4 November 2017, İstanbul, Istanbul Technical University, pp: 712-719.

Y1lmaz, S., Mutlu, E., Y1lmaz, H., 2018a. Quantification of thermal comfort based on different street orientation in winter months of urban city Dadaşkent. ISBN: 9789462612129, ISSN:05677572(print)24066168(electronic), Acta Horticulturae, 1215: 67-72.

Y1lmaz, S., Mutlu, E., Y1lmaz, H., 2018b. Alternative Scenarios For Ecological Urbanizations Using Envi-Met Model. Environmental Science and Pollution Research, 25 (26): 26307-26321. 